\title{
VirCA NET and CogInfoCom: Novel Challenges in Future Internet Based Augmented/Virtual Collaboration
}

\author{
Christian Weidig*, Adam Csapo ${ }^{\dagger \neq}$, Jan C. Aurich*, Bernd Hamann ${ }^{\S}$, Oliver Kreylos ${ }^{\S}$ \\ ${ }^{*}$ University of Kaiserslautern, Institute for Manufacturing Technology and Production Systems, \\ Kaiserslautern, Germany \\ ${ }^{\dagger}$ Budapest University of Technology and Economics \\ Dept. of Telecommunications and Media Informatics, Budapest, Hungary \\ ‡Computer and Automation Research Institute, Budapest, Hungary \\ ${ }^{\S}$ Institute for Data Analysis and Visualization (IDAV), University of California, Davis, USA
}

\begin{abstract}
Several challenges can arise during augmented/virtual collaboration. In this paper, we identify and classify some of these challenges from a cognitive infocommunications (CogInfoCom) point of view. The starting point of our analysis is the VirCA NET application, which was built on the Virtual Collaboration Arena (VirCA) and developed at the MTA SZTAKI. First, we demonstrate how VirCA and VirCA NET belong to the CogInfoCom paradigm and how they are also related to Future Internet. To highlight our ideas in a practical use-case, we identify key features of infocommunication in a collaborative scenario for building industrial production layouts. In the collaborative scenario, factory planning is defined as a multi-stakeholder and multi-domain challenge, which distributed planning teams have to face. Based on the features of VirCA NET and the specifics of the scenario, we outline a list of challenges, some of which are already solved by the system to some extent, and some of which remain to be solved in future work. The challenges are presented in relation to the theoretical background of CogInfoCom engines and CogInfoCom channels, in order to further strengthen the link between augmented/virtual collaboration and the goals of CogInfoCom.
\end{abstract}

\section{INTRODUCTION}

Cognitive infocommunications (CogInfoCom) is an emerging research paradigm which investigates the link between the research areas of infocommunications and the cognitive sciences, as well as the various engineering applications which have emerged as the synergic combination of these sciences [1], [2]. Through the active discussions of leading researchers who are involved in the establishment of CogInfoCom, it appeared that the technological evolution behind ICT, as well as the changing nature of infocommunications-based humanhuman and human-system interactions are driving various fields in the same direction. In particular, the information sciences contributing to ICT (most notably infocommunications) and the human-oriented cognitive sciences are expected to converge [3].

In this paper, the relevance of CogInfoCom for augmented/virtual collaboration is considered. The discussions are based on the Virtual Collaboration Arena (VirCA) system and a recent extension to the system. This extension allows users to view and collaborate through the same reality via distributed replications of VirCA (VirCA NET) [4], [5] Usually, CogInfoCom systems such as VirCA are based on technologies and components that are individually well-known to the wider community of engineers. However, the purpose of this paper is to show that the unique combination of these components gives rise to something bigger than the sum of its parts: a system that strongly supports Future Internet research and encapsulates the philosophy behind CogInfoCom. At the same time, new perspectives are opened up and new design challenges are introduced, which will inevitably change the way we relate to our interactions with infocommunications devices.

One perspective - which we will discuss in this paper - can be directly attached to the emerging demands coming from worldwide distributed production companies. Factories have to continuously adapt according to short product life cycles and agile worldwide markets [6]. The information technology in the range of mechanical engineering, over the last decade mainly expressed in the Digital Manufacturing approach, leads to a wide set of software tools and technologies. The objective is mainly to address challenges such as reduction of production development time and costs, mastering increased product complexity and quality, decreasing of response time in rapidly changing markets, etc. (for details see, e.g. [7]). Besides these considerations, the evolving spatial distribution of employees involved in planning cycles requires support for long-distance collaboration [8]. Factory planning in detail is therefore identified as one key domain to be supported by collaborative VR tools. The proposed main collaborative tasks are: modeling of the factory, validation of planning stages and oversight of optimization in the planned and/or existing production system [9]. However, a comprehensive approach to tackle spatially distributed factory planning by means of immersive, collaborative Virtual Reality (VR) is still not available [10].

The paper is structured as follows. In Section II, our previous work on the VirCA platform and VirCA NET is briefly introduced. In Section III, the collaborative scenario which 


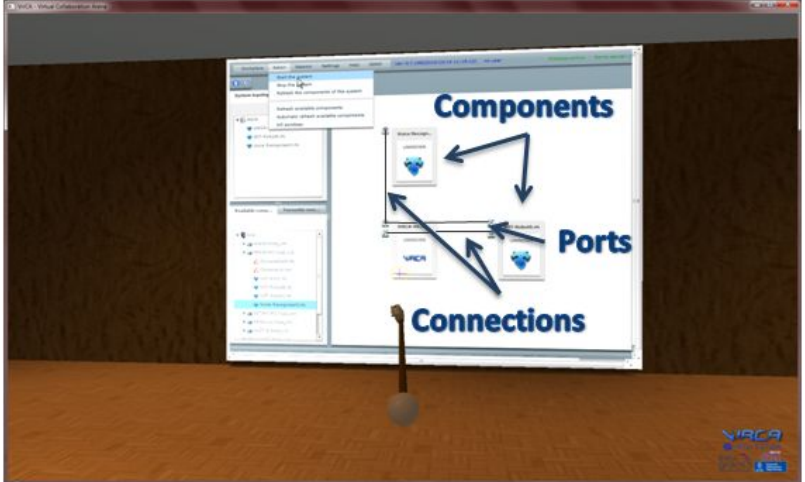

Fig. 1: Web-based system editor in a browser in VirCA

forms the foundation of this paper is described, along with the key challenges introduced by the collaborative scenario. Finally, in Section IV, these challenges are further elaborated and categorized based on regarding aspects of CogInfoCom.

\section{PREVIOUS WORK}

\section{A. The VirCA platform}

VirCA (Virtual Collaboration Arena) is an extensible 3D augmented/virtual collaboration platform developed at MTA SZTAKI. VirCA is based on an open-source visualization system (OGRE) and a de facto standard communications middleware (RT-Middleware): together, these two foundations make it possible to rapidly design, develop and deploy distributed collaborative scenarios [11].

The basic building blocks of a VirCA-based application are a set of distributed components which can be run independently of each other, and connected through a web-based system editor (Figure 1). Each component represents either an object in the environmnent, or a capability with which any object can be extended. Objects can be visualized in the 3D augmented/virtual environment provided by VirCA, and each object can be extended with any capability (Figure 2). The philosophy behind VirCA allows researchers and developers to:

- Actively share and collaboratively manipulate 3D content

- Collaborate in augmented ways - i.e., by synchronizing the $3 \mathrm{D}$ content and processes in VirCA with the real world

- Make use of flexible knowledge plug-and-play - i.e., cutting-edge computational methodologies created and developed at highly competent research facilities can be integrated into any VirCA based system, allowing for augmented/virtual devices to make use of state-of-the-art solutions in both controller hardware (applications exist for Nintendo Wii, Microsoft Kinect, etc.) and computational technologies (e.g. speech technologies, visionbased technologies, semantic reasoning technologies, etc.)

- Proactively participate in the development of future technologies - i.e. if a technology is not yet available or is still unreasonably expensive, it is possible to "virtualize" the technology in VirCA and investigate whether its addition to a physical system would bring the anticipated advantages

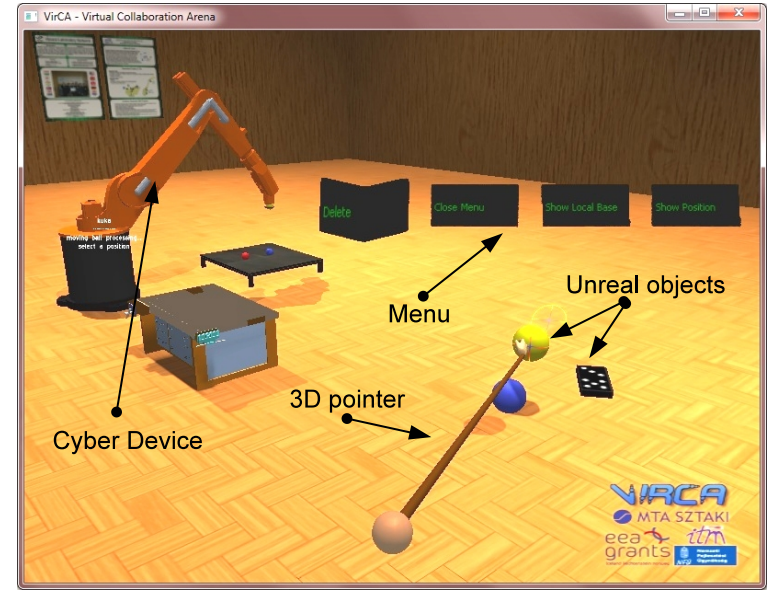

Fig. 2: Objects in VirCA

In summary, VirCA can be considered as a showcase platform both for CogInfoCom and for Future Internet in several aspects. First, it builds on de facto standards to create a freely extensible collaborative environment that merges together physical reality with virtual reality, and also allows for the use of truly multi-modal interaction schemes. Second, it serves as a testbed environment itself to test new ideas in both CogInfoCom and Future Internet. The emphasis which VirCA lays on virtual capabilities is very much in line with the CogInfoCom point of view, which aims to analyze and synthesize cognitive capabilities from a unified point of view, irrespective of whether those capabilities are natural (biological) or artificial.

\section{B. $\operatorname{VirCA} N E T$}

VirCA NET is the extension of the VirCA Platform for spatially distributed collaboration. Such an extension is facilitated by the fact that the whole philosophy behind VirCA is to allow for large-scale distributed component-based applications. Communication between the components is realized via the Internet. For the current use-case, multiple instances of VirCA are interconnected to create and share a common virtual environment. This is realized by remote connections (called VirCA NET connection) between one VirCA Master and several VirCA Slave clients. The VirCA Master serves as hub, maintaining the virtual space and organizing the VirCA Slaves. Cyber Devices are implemented for collaboration purposes, representing 3D objects (including robots, machines, physical objects, etc.) with specific geometries and behaviors . Cyber Devices are part of the shared space and can therefore be used and manipulated by each participant, independent of their physical locations.

\section{Collaborative Scenario AND Associated Challenges}

In this section, we outline two collaborative scenarios in order of growing complexity. The first scenario is currently implemented using VirCA NET, while the second scenario is more futuristic and has yet to be implemented. 


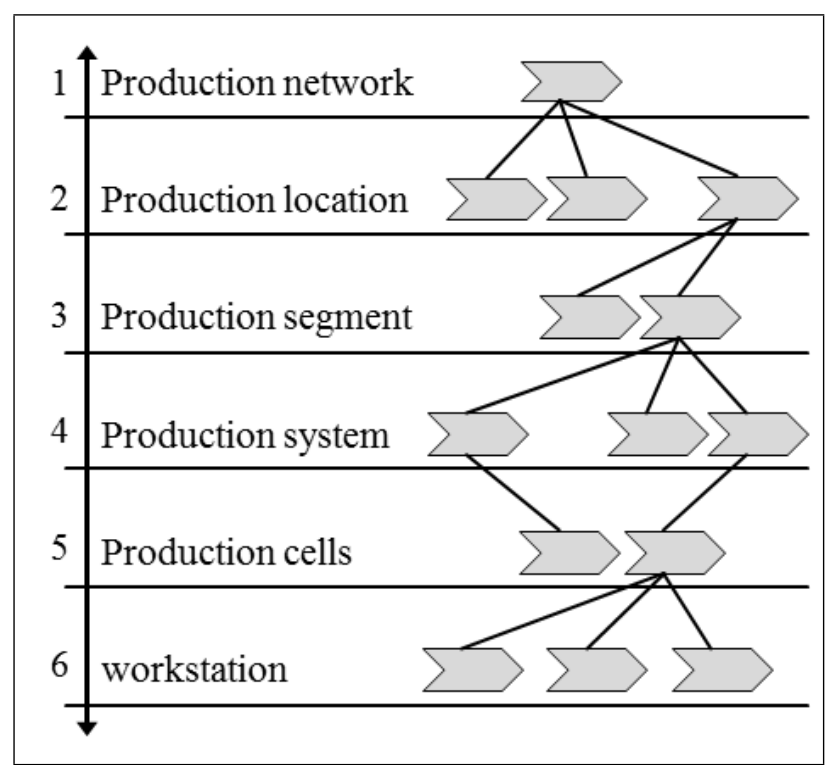

Fig. 3: Production levels in a manufacturing system [15]

\section{A. General factory planning tasks}

Factory planning is a multi-criteria problem where competitive advantages can only be generated if the system as a whole is optimized. Hence optimizations of material flows, resource utilization, factory layout planning and logistics at all factory levels have to be considered comprehensively [12], [13]. Therefore VR tools have been introduced throughout the research community, but also implemented into the industrial field. Nowadays in globalized and decentralized production systems VR tools must be enhanced by distance collaborative features as well [14]. To implement these features, the requirements coming from the digital factory planning must be known.

Factory layout planning can be understood as problem solving in a multidimensional design-space. On the one hand the several levels of a factory must be taken into account as also competitive requirements and constraint be satisfied (Fig. 3) [15]. On the other hand is this design problem characterized by the interaction between various divisions and responsible persons such as engineering, operations management, logistics and computer science (Fig. 4) [16].

The following use-case scenarios will detail out common basic conditions of factory planning projects and describe typical tasks. The general constraints should be kept in mind, when reliving these scenarios.

\section{B. Basic scenario}

In the basic scenario three pairwise remote connected locations are involved: Kaiserslautern (Germany), Budapest (Hungary) and Kosice (Slovakia). Each location represents a global entity (department) involved in a joint factory planning case. Kaiserslautern embodies the facility where the objective shop floor is located. Budapest will represent a robotic specialist and Kosice stands for the head office of the fictive company, where the central Industrial Engineering is located. Each of the locations VR-systems is connected to VirCA NET, and is

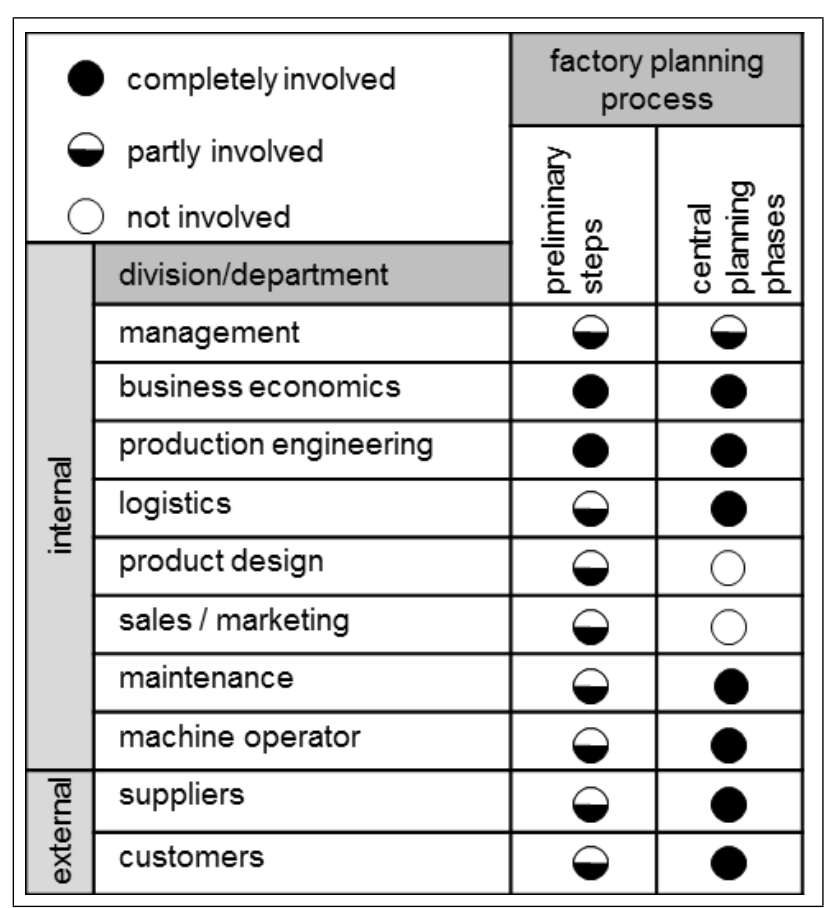

Fig. 4: Involvement of different divisions in the factory planning process [17]

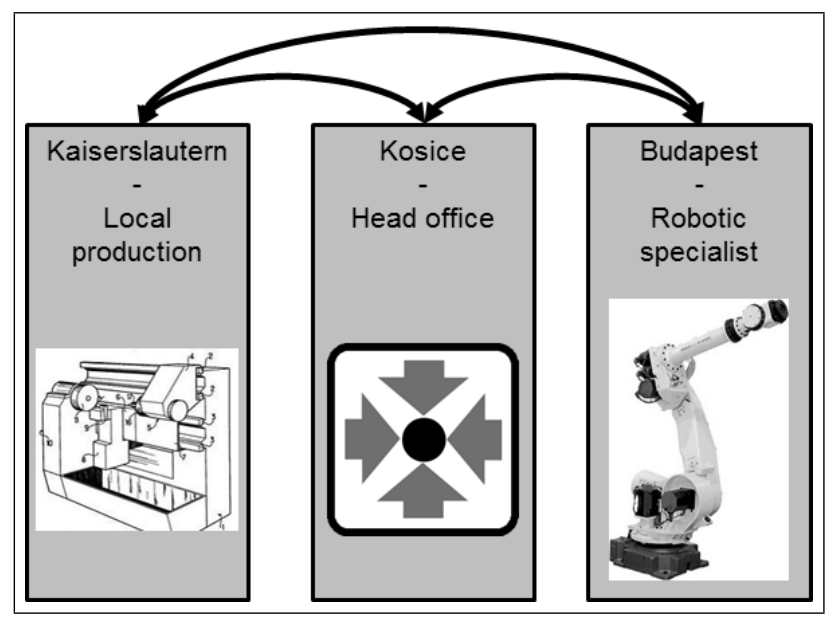

Fig. 5: Setup of the collaborative use-case

thus able to interact and collaborate using the hardware and software components running in different locations (figure 5).

In the collaborative scenario, a lathe machine - in Kaiserslautern - and a humanoid robot - physically located in Budapest - are added to VirCA NET. Together with the environmental shop floor are these elements forming the production system on which investigations are made. The virtual representations of the machine and robot can be directly controlled through VirCA NET from all three locations (this also allows the indirect control of the physical machine and robot through their virtual representation).

The objective of the planning situation is to optimize the shop floor in a way that the lathe, the robot and the environment interact in an ideal way. Therefore, the layout 
of the shop floor must be optimized, considering the special constraints coming from the three departments. To reach this objective personal skills and intrinsic know-how of the planning involved people must be merged through the collaborative system. Participants are allowed to change the position of the lathe and the robot in the virtual shop floor, to give commands to the robot (e.g., pick up workpiece, take workpiece to lathe, remove workpiece from lathe, etc.) and to give commands to the lathe (e.g., start operation). Each participant shall achieve the best solution for his point of view, without neglecting requirements from other departments.

\section{Complex scenario}

The overall goal of the complex scenario is to allow participants to collaboratively design the layout of an industrial shop floor. Although the basic scenario of the previous subsection is a step in this direction, there is the challenge of scaling the example to a fully detailed industrial environment, as well as other technical difficulties which need to be overcome in order to enable truly flexible collaboration.

The design of efficient layouts and routing schemes for industrial shop floors is a well researched subject that has both practical value as well as substantial theoretical background with a broad scope (apart from solving general problems using classical approaches [18], efforts have been made to also find adaptive solutions using e.g., stochastic methods [19] and soft-computing based methods [20]). Nevertheless, many of these approaches are inaccessible to the client that wishes to establish a new shop floor (e.g., leadership of a company). In this case, augmented/virtual collaboration becomes a viable approach to allow clients and system designers to collaboratively establish the shop floor layout and the main parameters of production.

In the complex scenario, the client opens one connection to the virtual shop floor, and the remotely located system designers open two connections. The interface to the virtual shop floor could be implemented by a 3D CAVE (as in the case of VirCA NET), or in the distant future it could be implemented by a volumetric 3D projection room. Participants are allowed to change the position of machines and other infrastructural elements (e.g., carts for storing working items, pathways for mobile robots and workers, etc.), and simulations of real production are also possible; however, the system must take into consideration a variety of constraints while the shop floor is being edited:

- the availability of supply sources for the industrial machines to be able to operate (e.g. power, water etc.)

- dependencies among machines and other infrastructure, dictating that they be placed in close proximity or far away from one another

- the working space of various robots in order to ensure a safe working environment

- the production process itself and the material flow through the shop floor

- connections to neighboring workstations and subsequent working areas

- connections to the logistic system in general
Additionally to these hard facts also soft skills must be facilitated in the complex scenario. The personal know-how exchange beyond explicit formalized information must be ensured. Tacit knowledge is a crucial factor to grant the comprehensive planning of factories. Therefore, features must be implemented and tested among their impact factor.

\section{Challenges associated with the scenarios}

Even if the scenarios are just an example out of the wide field of factory planning, they cover the key tasks and stand exemplary for the whole domain. The key challenges in the range of collaborative factory planning must be taken into account, while designing VirCA NET and executing the scenarios. Despite the detailed manifestations of the keychallenges will only occur during execution of the scenarios, their main characteristics can be identified in front. Shared model visualization, model interaction and means for human interaction are identified as three main categories.

The shared model visualization is the basic principle among a distance collaboration approach using immersive VR systems. VirCA NET must ensure a consistent representation of the virtual model for all involved entities, independent which users is in possession of the model parts. This is important for factory planning, to provide the equal planning stage to all users.

The user-machine interaction on the model level is the second important challenge. Users, equally where they are located, must be able to interact with the models. Changing the position of models is a basic operation while optimizing the shop floor layout. To express ones mind, it must be possible to adapt the layout for all users. The interaction with intelligent agents is another example for human-machine interaction. Predefined model behavior, like material flow simulation, must be accessible for all users as well.

The human-human interaction is the last of the three keychallenges. Users must be able to interact on a social level. Even if ideas can be transferred via the reorganization of the shop floor layout related models, the verbal expression of ideas is a key element for introducing and later on solving problems.

\section{Challenges During Collaboration from a COGINFOCOM PERSPECTIVE}

The challenges introduced in the previous section raise issues from two different perspectives:

- the design of CogInfoCom engines for the collaborating users of VirCA NET, including the specification of CogInfoCom triggers which lead to communication between the system and the user

- the design of CogInfoCom channels for the purpose of notifying the users of various events through multisensory signals which appeal to their cognitive capabilities

In this section, we briefly discuss the challenges related to each of these perspectives. 


\section{A. Challenges in terms of the CogInfoCom engine}

The CogInfoCom engine is defined as the component inside artificially cognitive systems which determines the dynamic properties of communication between the system and its environment [?]. The concept of CogInfoCom engines fits well into the VirCA concept, while VirCA is a distributed system in which each component (i.e., artificially cognitive system) is represented by a separate computational process.

One of the main purposes of the CogInfoCom engine is to determine what information the artificially system is to communicate to the environment and when. For example, each industrial machine and robot in the layout has to keep track of its internal state (dependencies to other devices and the fulfillment or violation of each of the dependencies) as well as the users' interactions with its position and orientation.

One of the concepts central to the functionality of the CogInfoCom engine is the kind of triggers the system recognizes and the kind of responses to the triggers that are given by the system. Triggers can be voluntary or involuntary - depending on whether the user activates them with an explicit goal or involuntarily as a side effect. As well as direct or indirect, depending whether the information on which the system provides a response is provided by the user or taken from contextual information (context fusion) [21]. In this respect, some possible issues are:

- Shared model visualization: it should be considered if the system should signal to each user possible inconsistencies in the shared model representation. E.g., if a user is working on a certain area of the shop floor and it is not yet clear what the effects will be, the system might signal not only the area they are working on, but also the parts of the shop floor that may be influenced through dependencies. Making sure that all of this feedback information is ecological enough so that it does not conflict with each user's cognitive capabilities is an important challenge.

- Feedback information during user-machine interaction: this kind of feedback can be generally categorized as voluntary and indirect; voluntary because the user will generally want to gain an understanding of the weight of the object they are moving, the dependencies they are violating when moving the object, etc., and indirect because the feedback information will generally be based on a fusion of pre-defined dependencies and the current layout (i.e., influenced by all of the collaborators involved). Due to the indirect nature of this communication, care must be taken to ensure that the user is given sufficient contextual information so that he/she will be able to understand what the feedback information means.

- User-user interaction: this point is somehow related to the point on shared model virtualization, i.e. what the other users are doing should belong to the shared model. However, ad hoc communication between the users should also be supported seamlessly.

\section{B. Challenges in terms of CogInfoCom channels}

CogInfoCom channels are defined as groups of iconic and/or abstract sensory signals (i.e., CogInfoCom messages) which convey information on the state of the same concept [?]. For example, if sounds are used to convey information on tactile percepts when touching surfaces in a virtual environment, then the group of all possible sounds which convey information on how rough a surface is would be an example of a CogInfoCom channel.

The main challenge concerning CogInfoCom channels is that once the CogInfoCom engine has decided when to communicate information and what type of information to communicate, the information has to be translated to sensory signals which appeal to the user's cognitive capabilities. In the context of the shop floor layout planning scenario, the following challenges can be listed:

- Shared model visualization: how should the system signal inconsistencies in the shared model representation? If a user is working on an area, should it be grayed out? How many shades of gray should be used? How should the difficulty of another user's task be represented? If a user needs help from another user, how should it be represented?

- Feedback information during user-machine interaction: how should the weight of an object be represented? How should conflicts be represented between what a user is doing and what other users have already done?

- User-user interaction: how can users influence which of their actions reaches the conscious level of other users' cognitive states? How can users influence (e.g., through what gestures) whether a given type of information is sent as a broadcast to all other users or as a unicast to a single other user? Which part of the screen should avatars of other users be located on? What effects can influence the appearance of other users' avatars and in what way?

\section{CONCLUSION}

In this paper, we identified some of the challenges which arise during augmented/virtual collaboration and we classified these challenges from a CogInfoCom perspective. The basis of our discussions was taken from the VirCA NET application built on the Virtual Collaboration Arena (VirCA) developed at MTA SZTAKI. We demonstrated how VirCA and VirCA NET belong to the CogInfoCom paradigm, and how they are also related to Future Internet, by identifying key features of infocommunication in a collaborative scenario for building industrial production layouts. Based on the features of VirCA NET and the specifics of the scenario, we drew a list of challenges - some of which are already solved by the system to some extent and some of which remain to be solved in future work. The challenges were presented in relation to the theoretical background behind CogInfoCom engines and CogInfoCom channels in order to further strengthen the link between augmented/virtual collaboration and the goals of CogInfoCom. 


\section{ACKNOWLEDGMENT}

This research was supported by the Hungarian National Development Agency, NAP project NKTH-KCKHA005 (OMFB01137/2008). The research leading to these results has received funding from the European Community's Research Infrastructure Action - grant agreement VISIONAIR 262044 - under the 7th Framework Programme (FP7/2007-2013).

\section{REFERENCES}

[1] P. Baranyi and A. Csapo, "Cognitive Infocommunications: CogInfoCom," in $11^{\text {th }}$ International Symposium on Computational Intelligence and Informatics (CINTI), 2010, pp. 141-146, Budapest, Hungary.

[2] _ , "Definition and Synergies of Cognitive Infocommunications," Acta Polytechnica Hungarica, vol. 9, pp. 67-83, 2012.

[3] G. Sallai, "The Cradle of Cognitive Infocommunications," Acta Polytechnica Hungarica, vol. 9, pp. 171-181, 2012.

[4] P. Galambos and P. Baranyi, "VirCA as Virtual Intelligent Space for RT Middleware," in IEEE/ASME International Conference on Advanced Intelligent Mechatronics, 2011, pp. 140-145.

[5] http://www.virca.hu.

[6] E. Westkämper, C. Constantinescu, and V. Hummel, "New paradigm in manufacturing engineering: Factory life cylce," Production Engineering Research and Development, vol. 13, no. 1, pp. 143-146, 2006.

[7] G. Chryssolouris, D. Mavrikios, N. Papakostas, D. Mourtzis, G. Michalos, and K. Georgoulias, "Digital manufacturing: History, perspectives, and outlook," Journal of Engineering Manufacture, vol. 222, pp. 451462,2008

[8] C. Redaelli, G. Lawson, M. Sacco, and M. D’Cruz, "Difac: Digital factory for human oriented production system," InTech, pp. 339-354, 2009.

[9] A. Nee, S. Ong, G. Chryssolouris, and D. Mourtzis, "Augmented reality applications in design and manufacturing," CIRP Annals - Manufacturing Technology, no. 61, pp. 657-679, 2012.

[10] N. Menck, X. Yang, C. Weidig, P. A. Winkes, C. Lauer, H. Hagen, B. Hamann, and J. C. Aurich, "Collaborative factory planning in virtual reality," in The 45th CIRP Conference on Manufacturing Systems, Athens, Greece, May 2012.

[11] P. Galambos and P. Baranyi, "VirCA as Virtual Intelligent Space for RT-Middleware," in IEEE/ASME International Conference on Advanced Intelligent Mechatronics, 2011, pp. 140-145.

[12] W. Kühn, Digitale fabrik - Fabriksimulation für Produktionsplaner. Hanser-Verlag, Munich, 2006.

[13] P. Nyhuis, S. Wulf, T. Klemke, and B. Hirsch, "integrative factory, technology, and production planning - systemizing the information transfer on the operational level," Production Engineering - Research and Development, vol. 4, no. 2, pp. 231-237, 2010.

[14] G. Vigano, L. Greci, and M. Sacco, "Giove virtual factory: the digital factory for human oriented production system," in Proceedings of the 3 h CIRP International Conference on Changeable, Agile, Reconfigurable and Virtual Production, Munich, Germany, oct 2009, pp. 748-757.

[15] H.-P. Wiendahl, P. Nyhuis, and W. Hartmann, "Should cirp develop a production theory? motivation - development path - framework," in Conference on Sustainable Production and Logistics in Global Networks, Vienna, Austria, may 2010, pp. 3-18.

[16] R. P. Smith and J. A. Heim, "Virtual facility layout design: the value of an interactive three-dimensional representation," International Journal of Production Research, vol. 37, no. 17, pp. 3941-3957, 1999.

[17] T. Gase and U. G. und A. Krauss, "Integrierte struktur- und layoutplanung," werkstattstechnik online, vol. 5, no. 96, pp. 314-320, 2006.

[18] Bauer, Bowden, Browne, Duggan, and Lyons, Shop Floor Control Systems - From Design to Implementation. Chapman \& Hall, 1991.

[19] G. Meng, S. Heragu, and H. Zijm, "Reconfigurable Layout Problem," Interrnational Journal of Production Research, vol. 42, pp. 4709-4729, 2004.

[20] P. Peeters, H. van Brussel, P. Valckenaers, J. Wyns, L. Bongaets, M. Kollingbaum, and T. Heikkila, "Pheromone Based Emergent Shop Floor Control System for Flexible Flow Shops," Artificial Intelligence in Engineering, vol. 15, no. 4, pp. 343-352, 2001.

[21] A. Csapo and P. Baranyi, "A Taxonomy of CogInfoCom Trigger Types in Practical Use Cases," in 3rd IEEE International Conference on Cognitive Infocommunications (in press), 2012. 